\title{
Main Factors That Facilitate Second Language Learning With Learning and Teaching Experience
}

\author{
Wenyi $\mathrm{Li}^{1}$ \\ ${ }^{1}$ University of Liverpool, Liverpool L69 3BX, UK \\ Correspondence: Wenyi Li, University of Liverpool, Liverpool L69 3BX, UK. E-mail: 709005816@qq.com
}

Received: November 1, 2021

Accepted: November 23, $2021 \quad$ Online Published: November 26, 2021

doi:10.20849/ajsss.v6i4.955

URL: https://doi.org/10.20849/ajsss.v6i4.955

\begin{abstract}
There are many factors that influence and promote second language learning and this research examines how to promote second language learning and teaching by exploring three main individual factors, namely motivation, anxiety and enjoyment. By understanding students' extrinsic motivation, teachers can use rewards or foster a sense of responsibility in learners to stimulate their latent interest. Although anxiety is generally regarded as a negative factor in learning, it can be reduced and language learning facilitated by studying the mechanisms of anxiety. The opposite of anxiety is enjoyment, and teachers can find a rewarding and enjoyable way to encourage students to make progress. Second language learning can therefore be facilitated through a range of research into the three important individual differences in motivation, anxiety and enjoyment.
\end{abstract}

Keywords: second language learning, motivation, foreign language learning, anxiety, enjoyment

\section{Introduction}

With the rapid development of the society, more and more people start to investigate second language acquisition (SLA), which correspondingly promotes the increase of the quantity of the research and even facilitates the grow of the area of SLA. This further gives people more chances and details to understand how difficult and complicated for second language (L2) learners to study L2 (Peter, 1989). When it comes to L2 learners' study, there are many researches that focus on the similarities of different L2 learners such as their learning methods or their attitudes of study. However, it is also important for people to investigate the differences of L2 learners' learning. "Why do individuals differ so much in second language attainment success? After all, every healthy human being in an intact social environment masters a first language to a degree of fluency that, in other skill domains, would be recognized as elite or near elite levels..." (Segalowitz, 1997: 85). Different learners have different characteristics, this leads individuals differ when they are learning. And these factors might have various influences for learners. Therefore, what are the main factors that can facilitate foreign language learning and how they facilitate L2 learning will be discussed in this essay. Firstly, the motivation factor will be discussed, and it includes two parts, integrative motivation \& instrumental motivation and intrinsic motivation \& extrinsic motivation. Secondly, the anxiety factor will be explained. This part is mainly about how anxiety hinders L2 learning. However, teachers can utilize this theory to reduce and avoid students' anxiety and help them get improved. Lastly, enjoyment will be introduced. It is a positive factor that opposite to anxiety. After studying how anxiety influences foreign language learning, it will be easier to explain enjoyment and how to create enjoyable learning environment.

\section{Motivation}

Gardner and Lambert (1972) state that motivation plays an important role in many aspects of the process of SLA, so it is really useful to investigate how the motivation facilitates L2 learners about the acquisition of the second language (SL). Motivation is generally be considered as the desire and purpose to prompting L2 learning and the energy to keep it, it could be considered as a quality which highly contributes to some people's daily life while exist little or even none in others' lives (Ortega, 2014: 168). This means motivation is a kind of individual feature which might be a power for people to construct a goal and have the desire to face the task and even have the energy and encouragement to complete the goal, then they might have more ability and chance to success. For some people, they might have enough motivation to help them make efforts to work or study and keep it, it is a positive and valuable quality for people to become more and more outstanding. However, for others, they may just have little or even have no motivation, this might widen their competence gap between them with those who 
are motivated everyday. Therefore, if learners are motivated in the process of their second language learning, their study competence might be highly facilitated. What's more, "motivation, defined as the impetus to create and sustain intentions and goal-seeking acts, is important because it determines the extent of the learner's active involvement and attitude toward learning (Pandey, 2005, p.79). This means motivation is an important motivate power of learning. When learners are studying, they might need initiative and positive attitude to learning, and motivation can help learners to produce initiative and positive attitude. So motivation really plays a significant role in L2 acquisition. In the following part, there will be two parts of motivation, integrative motivation \& instrumental motivation and intrinsic motivation \& extrinsic motivation.

\subsection{Integrative Motivation \& Instrumental Motivation}

One model of motivation is socio-educational model which includes integrative motivation and instrumental motivation. These two motivations are both facilitation to foreign language learning. Gardner and Lambert (1972) are considered as the pioneers in the area of researching the second language acquisition and motivation. They included two motivation factors-- integrative motivation and instrumental motivation in their research. And in their investigation, learners are asked to focusing on complete targets with these two motivations. According to Gardner and Lambert (1972), the difference between instrumental motivation and integrative motivation is instrumental motivation focus more on pragmatic purpose and it is for learners who need language while integrative motivation address more on use language to communicate and it is for pure language interest.

\subsubsection{Instrumental Motivation}

Gardner and Lambert (1972) claim that instrumental motivation can usually be considered as the kind of motivation for those learners who want to learn a second language for education or for seeking opportunities of job. This means L2 learners with instrumental motivation wish to achieve their aim through attaining a second language and they usually focus more on the actual value and benefits of learning a new language, these learners usually have direct purpose when studying and be more passive compared with learners who study with integrative motivation. For an example, when a person desire to find a job with many competitors who are required to be good at a new foreign language or want to be employed abroad, or a student plan to study abroad, then there is a need and motivation for them to learn a second language.

There is an example in real life for the view above. It is about two years ago when I was studying IELTS in my mother country-China. I studied in an school of teaching foreign language. I remember there is a man about thirty years old who was studying Korean next to my classroom and he wanted to seek a job in Korea. In order to work and life in Korea, he had to study Korean hardly because there would be more and better chance for job if his language competence is excellent. Sometimes I had my self- study with him and I found he spent much more times on study than others and even improved more quickly than others who just considered studying Korean as their major. The man learned Korean hard and made progress quickly was because he regarded the language learning as a way to achieve his aim of seeking a job. He was motivated by instrumental motivation with a direct and pragmatic purpose to improve.

\subsubsection{Integrative Motivation}

Compared with instrumental motivation, integrative motivation is usually associated with the L2 learners' interest in get connection with other language community and culture. According to Shirbagi (2010), integrative motivation is usually for some learners who aim to become significant participators in the foreign language society or want to make cultural communication with other community members. In other words, integrative motivation is used by language learners who have more interest in social interaction. It is said that in socioeducational model, integrative motivation is a power of promoting the acquisition of L2. This is because the process of studying with integrative motivation means the process of participating learning actively (Gardner and MacIntyre, 1991). Moreover, according to Gardner (1983), the research show that for language learners who study with integrative motivation, not only can they do better in foreign language learning but also they can perform more actively and positively in class. And if there is any chance, they might choose to take part in other culture communities where they can interact with those community members. What's more, these kinds of students are even less likely to stop their language acquisition for several years. I agree with these ideas and I also have an example in real life to explain it more clearly. There is an experience that I have had. One year ago, when I was a teaching assistance of a foreign language institution, there was a student of mine who liked playing guitar and singing songs and dreamed to create a music band with foreigners in America where he would study in the future. In order to have an excellent ability of communicating with local Americans and know more about American culture, he had enough passion for learning English. In our class, he always interacted actively with teacher and classmates and made much more efforts than others after class. Now he has had a small band with 
several local people and even has organized tours in different areas in America. However, he still has much passion for improving his English competence during his every chance of communicating with local Americans. It is his wish of interacting more with other community members and wish of taking more social activities that motivated him to success. So the strong power of learning English better for him is integrative motivation.

\subsection{Intrinsic Motivation \& Extrinsic Motivation}

More and more educators or researchers are being aware of the vitally important meaning of intrinsic and extrinsic motivation for the development of education. According to Ryan \& Deci (2000), intrinsic motivation and extrinsic motivation reflect the relationship between motivation and the basic needs of human initiative, relevance and competitiveness. So these two types of motivation are being studied extensively. Human have the need of being motivated to be improved and stimulated. However, different people have different motivations, this is not only about the quantity but about the types (Ryan \& Deci, 2000). This means different amount of motivation could give people different levels of stimulation and different types of motivations are usually related to people's attitude of their aims. In addition, Ryan \& Deci (2000) also indicate that people will have different performance if being motivated separately by intrinsic motivation and extrinsic motivation. For an example, a student study hard might because his or her interest and curiosity or because the reward from parents or teachers, the reasons and motivation types are quite different. Consequently, it is beneficial to know how to stimulate L2 learners in a proper way by investigating the how these two types of motivations work for learners.

\subsubsection{Working Theory of Intrinsic Motivation and Extrinsic Motivation}

Intrinsic motivation refers to the kind of motivation that powered by human inherent wish and interest (Ryan \& Deci, 2000). It is enjoyment and curiosity etc. motivated active actions to appear without any outside pressure and the performances stimulated by intrinsic motivation can also make people be enjoyable and feel satisfied. According to White (1959), in his experimental research, there are still many organisms have interest and desire of learning and have enjoyment even there is no stimulation and encouragement. This means some performances happen naturally and actively, it is automatically but not instrumentally. From birth, people are active, curious and playful animals in their healthiest state, showing readiness to learn and accept new knowledge, and they don't need additional rewards incentives to do so (Ryan \& Deci, 2000). Consequently, a person can improve competence and learn new knowledge because of his or her inherent interest and desire motivated, this is the benefit of intrinsic motivation for language learning. Compared with intrinsic motivation means to do something powered from innate interest, the other motivation-- extrinsic motivation means to do something stimulated by outside power, it will cause or lead to a separate result. According to deCharms (1968), compared with intrinsic motivation, extrinsic motivation is usually described as a indigent motivation which might lead to students study with no interest and a sense of resistance in many research or literature even it really has its power. However, Deci \& Ryman (1985) indicate in self-determine theory that extrinsic motivation can also motivate students accept knowledge with willingness because of some valuable and pragmatic outcome. In consequence, compared with some passive actions powered by extrinsic motivation, there are also some actions arise and motivated by extrinsic motivation because of students' active intention. Therefore, for some students might do not have intrinsic motivation, educators and teachers can use an appropriate way by understanding how to stimulate students passion and willingness with extrinsic motivation to encourage students make progress in learning.

\subsubsection{Learning and Teaching Experience}

When I was in my high school, my most favorite major is English. I thought English is romantic and it has its rhythm when it is spoken. When I spoke and read English, I found the feeling was like singing a song, it was so enjoyable and relaxing. As a result, I had a strong interest in English and wanted to do better in it. In my spare time, I paid most of it for learning English such as practicing spoken English, learning more new and high level words and watching English movies. In this way, I made rapid progress in English than other majors. In a word, I did better in English than other majors was stimulated and prompted by my inherent interest and inspiration, it was an active and enjoyable process. This is the benefit of foreign language learning motivated by intrinsic motivation. There is also an example for extrinsic motivation. When I was an English teacher, there was a naughty boy in my class who did not interested in studying English at all. He said he was nearly forced by his parents to study English and his dream was to become a doctor, which had no connection with learning English. In order to encourage him to study English, I told him only study English well can he be accepted by higher level medical school and accept higher quality medical education, and this can give him an opportunity to become an excellent doctor. Therefore, Studying English well became a responsibility and a valuable effort for him. Furthermore, I would give him reward like reducing homework or playing computer games for an hour to encourage and stimulate him keep low but consistent interest in studying English. In this way, the boy's 
competence of English was improved previously. So if extrinsic motivation is implemented appropriately, it can make vital contribution to L2 learning.

\section{Foreign Language Anxiety}

It is believed that the foreign language learners often find it is difficult for them to absorb knowledge when they are feeling anxious in the process of learning and teaching in the foreign language classroom. Therefore, anxiety can affect the acquisition of a second language (Yusof and Yasmin, 2013). So it is necessary to raise the awareness of second language anxiety (FLA). Although FLA is a negative factor, its impact on the second language acquisition process should not be underestimated. Only by understanding what negative emotions are, can we take proper measures to promote the progress of second language learning. Dörnyei and Ryan (2015) pointed out that emotions really do matter in daily lives, however, second language acquisition learners usually do not pay much attention to their emotions when they are studying a new language. And this situation is related to the cognitivism tradition. Therefore, it is vital to investigate and pay attention to this problem in the area of second language acquisition.

\subsection{How the Anxiety Has Influences on SLA}

According to Maclntyre (2017), foreign language anxiety can seriously damage to mental health. In the process of learning, learners not only rely on mental support but also psychological and spiritual support. If SLA affects mental health, it will seriously affect learning. Krashen (1982) indicate that there is a filter of L2 learners' emotion and it can control the degree of learners' openness for the knowledge they are learning. When the filter is turned on, the learner's ability to absorb and learn the second language will be reduced, and quantity of knowledge being learned into the brain will be reduced. This means that when students have anxiety emotion which can stimulate the switch of the filter, learners tend to have a resistance and a negative attitude towards language absorption, this will further cause the learners' learning ability and efficiency to be reduced. Moreover, Maclntyre and Gregerson (2012) also suggest that negative emotions might cause to disturb students' attention while learning even limit the ability of new knowledge intake. So if there are anxiety and negative emotions in the learning process, it will be difficult for learners to concentrate on studying seriously, which will affect the improvement and progress of his language competence. Therefore, it can be seen from the aspects of mental health, emotional factors and attention that FLA can really great resistance to learners' language learning process and progress.

\subsection{Learning Experience}

There was a learning experience of mine when I was studying IELTS in China for the application for Liverpool. Once I was preparing for my upcoming IELTS exams, I was really much more anxious than each time before. When the teacher are reminding students the skills of how to deal with the reading part, I was too nervous about the exam and could not focus on and listen to the teacher carefully. I even started to feel the shortness of breath and horror. That feel have less desire and competence to absorb and accept knowledge. I even started to resist studying and have a thought of flinching. In a word, FLA had an influence on my study and could not be ignored. In mental aspect, FLA made me felt uncomfortable and nervous. Physically, it made me unable to concentrate and reduce my learning efficiency. In the aspect of affection, I became resistant to learning and my learning ability was reduced.

\subsection{Summary and Critical Thinking}

Though anxiety might hinder learning progress to some degree, such as disturb students' attention, influence their emotion and even have drawbacks for their mental health, teachers and educators and utilize the knowledge of disadvantages of anxiety to reduce students' anxiety in several ways. This might be a wise method to investigate how to encourage students learning. And this will be introduced in the following context.

\section{Enjoyment}

Compared with the foreign language anxiety that has been discussed in the above context, enjoyment is an positive emotion that is of importance to SLA. During the process of learning and teaching foreign languages, we can create positive emotions and relaxing learning atmosphere by investigating the negative emotions and anxiety to promote second language acquisition. It could be much easier for L2 students to adjust different events in the classroom if they are studying with positive emotions and they could even have stronger perception of language input, which can help them make further progress in SLA. In addition, positive emotions could positively encourage learners to cultivate their long-term ability of adjusting and their inspiration of enduring hardness, stimulating them to try to take risks without any hesitation of failure. And one of such complex positive motivations is enjoyment (Maclntyre and Gregerson, 2012). 
For the emotional filter mentioned, Krashen (1982) also claim that it might be wisely to weaken the learners' filtering ability and reduce the times of opening the filter, so teachers can try to stimulate students' interest in learning and provide students a relaxing and low-anxiety language learning environment where learners could be motivated to establish self-esteem and have more confidence. In this case, students are in an enjoyable learning environment and have a low level anxiety, which helps them to be willing and open to accept new knowledge. Just as Schumann (1978) notes in her acculturation hypothesis "he is psychologically open to the TL such that input to which he is exposed becomes intake". Therefore, if a student is willing to accept new knowledge actively, then the knowledge that is exposed to him can be truly absorbed by him. Furthermore, Fredrickson (2003) also indicates in his broaden-and-build theory that positive emotions can contribute to "broaden people's momentary thought-action repertories and build their enduring personal resources, ranging from physical and intellectual resources to social and psychological resources". So building positive emotions can make contribution to many aspects of learners. Moreover, psychologist suggest that positive motivations can facilitate learners' language learning by stimulate their ability of being curious and creative and also stimulate their interest to explore deeply while learning (Dewaele, Magdalena and Saito, 2019). If L2 learners are provided with a relaxing environment and studying foreign language with enjoyment such as some games or interesting questions in the language class, they might be encouraged to be more willing to accept knowledge and have more interest to investigate and even further create new ideas about the new knowledge. So enjoyment is really a worthwhile factor that facilitates learners' second language learning.

\subsection{Teaching Experience}

When I was a teaching assistance, I really found that enjoyment is an significant element of reducing students' sense of anxiety and stimulating their study willingness. Once I started my class with helping students consolidating the memory of some English words that had had been learned last class, I wrote some questions on the blackboard and asked students to answer. But I found some students could not remember the words clearly, or even suddenly forgot the meaning of the words because they of nervous. In addition, there are some students could not concentrate when I was asking others. Therefore, I realized that this teaching environment might was not comfortable and proper for them. I changed my teaching method. I showed students several pictures and videos to and asked them to guess the meaning of the words that appeared, then asked them to discuss with each other and use these words to make easy and short sentences. This was like a relaxing game and students could quickly immerse themselves in the enjoyment of guessing and discussion with less anxiety and less attention disturbed. Some students even started to learn more new words actively which means they were learning with willingness. This class finished successfully and students really enjoyed it and improved quickly. This example can be a strong and clear demonstration for explaining enjoyment is a positive emotion which can contribute to reduce anxiety and facilitate students' foreign language learning.

\section{Conclusion}

There are really various factors that influence or facilitate second language learning. In this essay, there are three main individual factors have been explained, they are motivation, anxiety and enjoyment. Motivation is an element which can not be ignored relating to higher ability of SLA, In this essay, the motivation factor includes two parts, integrative motivation \& instrumental motivation and intrinsic motivation \& extrinsic motivation. In integrative motivation is the kind of motivation that can motivate learners to learn L2 because of their wish of come close to other culture and community, while instrumental motivation refers to learners study hard because their pragmatic desire. Therefore, for different students with different instrumental and integrative motivation, they could perform differently in the process of study. And teachers can also use different teaching methods to encourage learners to improve. Compared with extrinsic motivation, intrinsic motivation is a more strong and direct factor that can contribute to L2 learning. Though extrinsic motivation is a more impoverished factor, teachers can try to utilize reward or tap learners' responsibility to encourage there potential interest. For the factor of anxiety, even it is described as a negative element for study in most research, learners and educators can try to apply wise ways to control and reduce anxiety by understanding how anxiety influence learners during the process of learning. Enjoyment is the last one to be introduced, which is an opposite factor to anxiety. By investigating what disadvantages that anxiety has for studying, teachers can find a beneficial and enjoyable way to reduce students' anxiety or nervous and encourage them to get improved. Therefore, motivation, anxiety and enjoyment are three vital individual differences that can facilitate second language learning. However, there are still some limited researches about anxiety because there are few researches about the advantages that anxiety has for L2 learning. It could be wondered and assumed that anxiety can stimulate foreign language learning to some degree. For some learners, a little anxiety might become a stimulation and pressure to encourage them work harder. This could be a topic to investigate in the future. 


\section{References}

deCharms, R. (1968). Personal causation. New York: Academic Press.

Deci, E. L., \& Ryan, R. M. (1985). Intrinsic motivation and self-determination in human behavior. New York: Plenum. https://doi.org/10.1007/978-1-4899-2271-7

Dewaele, J., Magdalena, A., \& Saito, K. (2019). The Effect of Perception of Teacher Characteristics on Spanish EFL Learners' Anxiety and Enjoyment. The Modern Language Journal, 103(2), 412-427. https://doi.org/10.1111/modl.12555

Dörnyei, Z., \& Ryan, S. (2015). The psychology of the second language learner revisited. New York: Routledge. https://doi.org/10.4324/9781315779553

Fredrickson, B. L. (2003). The value of positive emotions. American Scientist, 91, 330-335. https://doi.org/10.1511/2003.4.330

Gardner, R. C., \& Lambert, W. E. (1972). Attitudes and motivation in second-language learning. Rowley, Mass: Newbury House Publishers.

Gardner, R., \& MacIntyre, P. (1991). An Instrumental Motivation in Language Study: Who Says It Isn't Effective? Studies in Second Language Acquisition, 13(1), 57-72. https://doi.org/10.1017/S0272263100009724

Krashen, S. (1982). Principles and practice in second language acquisition. Oxford, UK: Pergamon Press.

MacIntyre, P. D. (2017). An overview of language anxiety research and trends in its development. In C. Gkonou, M. Daubney, \& J.-M. Dewaele (Eds.), New insights into language anxiety: Theory, research and educational implications (pp. 11-30). Bristol, UK: Multilingual Matters. https://doi.org/10.21832/9781783097722-003

MacIntyre, P. D., \& Gregersen, T. (2012). Emotions that facilitate language learning: The positive broadening power of the imagination. Studies in Second Language Learning and Teaching, 2, 193-213. https://doi.org/10.14746/ssllt.2012.2.2.4

Ortega, L. (2014). Understanding second language acquisition (ebook ed., p. 168). Hoboken: Taylor and Francis. https://doi.org/10.4324/9780203777282

Pandey, V. C. (2005). Intelligence and motivation. Delhi: Isha Books.

Ryan, R. M., \& Deci, E. L. (2000). Intrinsic and extrinsic motivations: Classic definitions and new directions. Contemporary Educational Psychology, 25, 54-67. https://doi.org/10.1006/ceps.1999.1020

Schumann, J. (1978). The acculturation model for second-language acquisition. In R. Gingras (Ed.), Second-language acquisition and foreign language teaching (pp. 27-50). Arlington, VA: Center for Applied Linguistics.

Segalowitz, N. (1997). Individual differences in second language acquisition.

Shirbagi, N. (2010). An exploration of undergraduate student's motivation and attitudes towards English language acquisition. Journal of Behavioural Sciences, 20(2), 1-15.

White, R. W. (1959). Motivation reconsidered. Psychological Review, 66, 297-333. https://doi.org/10.1037/h0040934

Yusof, M., \& Yasmin, S. (2013). Second language anxiety among year 5 primary school learners in SK King George V.

\section{Copyrights}

Copyright for this article is retained by the author(s), with first publication rights granted to the journal.

This is an open-access article distributed under the terms and conditions of the Creative Commons Attribution license (http://creativecommons.org/licenses/by/4.0/). 